\title{
AS “ADAPTAÇÕES RAZOÁVEIS” E A EFETIVAÇÃO DO DIREITO SOCIAL À EDUCAÇÃO
}

\section{THE "REASONABLE ADAPTATIONS" AND THE EFFECTIVENESS OF THE SOCIAL RIGHT OF EDUCATION}

\author{
Marcos Alves da Silva ${ }^{1}$ \\ Pedro Henrique Esmanhotto ${ }^{2}$ \\ Juliano Siqueira de Oliveira ${ }^{3}$
}

\section{Resumo}

O presente artigo abordará, em primeiro lugar, os direitos humanos e fundamentais, sua relação com a dignidade humana, a fim de sufragá-lo na condição de direito marcado pela inalienabilidade, irrenunciabilidade e limitabilidade. Em segundo momento será realizada a contextualização do direito social à educação no ordenamento jurídico brasileiro e, assim, adentrando-se à educação inclusiva, modalidade educacional imprescindível para a afirmação da dignidade humana das pessoas com deficiências. A efetivação dos amplos direitos assegurados pela legislação no que tange à educação especial, contudo, pode gerar conflitos e dificuldades para as instituições que integram a rede privada de ensino, na medida em que estas encontram como única fonte de receitas para a manutenção de suas atividades os valores pagos por seus contratantes a título de contraprestação pelos serviços educacionais eu lhes são prestados. Neste cenário, o presente artigo, a partir de metodologia dedutiva e revisão bibliográfica, abordará as adaptações razoáveis, sua origem e recepção no ordenamento jurídico pátrio, propondo sua utilização na condição de elemento capaz de propiciar o equilíbrio entre as necessidades dos estudantes e a impossibilidade de se acarretar ônus desproporcional e indevido potencialmente capaz de colocar em risco a própria sustentabilidade financeira da instituição de ensino.

\footnotetext{
${ }^{1}$ Doutor em Direito Civil pela Universidade do Estado do Rio de Janeiro - UERJ (2012). Mestre em Direito pela Universidade Federal do Paraná - UFPR (2001). Graduado em Direito pela Universidade Federal do Paraná (1995). Advogado. Professor da Escola da Magistratura do Paraná - EMAP. Professor da Fundação Ministério Público do Estado do Paraná - FEMPAR. Professor Permanente do Programa de Mestrado em Direito Empresarial e Cidadania do UNICURITIBA. Realiza estágio Pós-Doutoral na Universidade Nova de Lisboa (2016/2017).

${ }^{2}$ Advogado e mestrando do Programa de Especialização Stricto Sensu do Centro Universitário Curitiba, Mestrado em Direito Empresarial e Cidadania.

${ }^{3}$ Advogado e mestrando do Programa de Especialização Stricto Sensu do Centro Universitário Curitiba, Mestrado em Direito Empresarial e Cidadania.
} 
Palavras-Chave: Direitos Fundamentais. Direito Social à Educação. Educação Especial e Inclusiva. Adaptações Razoáveis.

\begin{abstract}
This article will deal first with human and fundamental rights and their relationship with human dignity, in order to provide for it as a right characterized by inalienability, inalienability and limitation. Secondly, the contextualization of the social right to education in the Brazilian legal system will be carried out and, thus, entering into inclusive education, an essential educational modality for affirming the human dignity of persons with disabilities. The implementation of the broad rights guaranteed by the legislation regarding special education, however, can generate conflicts and difficulties for the institutions that integrate the private education network, as these are the only source of income for the maintenance of their activities the amounts paid by their contractors as consideration for the educational services I render to them. In this scenario, this article will deal with reasonable adaptations, their origin and reception in the legal order of the country, as an element capable of balancing the needs of students and the impossibility of incurring disproportionate and undue burdens potentially capable of jeopardizing one's own financial sustainability of the educational institution.
\end{abstract}

Key Words: Fundamental Rights. Social Right to Education. Special and Inclusive Education. Reasonable adaptations.

\title{
1. INTRODUÇÃO
}

Ao tratar do tema direitos humanos, recorrente é a situação de sua confusão com os direitos fundamentais. Contudo, não são eles sinônimos, fazendo-se necessário, de início, traçar a diferenciação entre ambos. Inicialmente, o conceito de direitos humanos para HERKENHOFF (1994, p.30):

Por direitos humanos ou direitos do homem são, modernamente, entendidos aqueles direitos fundamentais que o homem possui pelo fato de ser homem, por sua própria natureza humana, pela dignidade que a ela é inerente. São direitos que não resultam de uma concessão da sociedade política, pelo contrário, são direitos que a sociedade política tem o dever de consagrar e de garantir. 
Pode-se dizer, portanto, que os direitos humanos tratam daqueles direitos aos quais todo e qualquer ser humano tem direito pelo simples de ser uma pessoa humana, de existirem. Independem, portanto, de previsão no ordenamento da nacional, eis que já garantidos pela comunidade internacional. Neste sentido, o ilustre professor COMPARATO (2003, p.224)

A vigência dos direitos humanos independe de sua declaração em constituições, leis e tratados internacionais, exatamente porque se está diante de exigências de respeito à dignidade humana exercidas contra todos os poderes estabelecidos, oficiais ou não.

Doutra monta, direitos fundamentais são aqueles específicos e internos de cada país, mas que são igualmente caros. Desta forma, ao passo que os direitos humanos são inerentes a todos os seres humanos, os direitos fundamentais variam de um país para outro, sendo necessária sua positivação nas Constituições de cada país de forma individualizada, como dito por LEITE (2011, p. 34). Ainda, no mesmo sentido, MORAES (2011, p. 2) aduz que os direitos fundamentais:

Se colocam como uma das previsões absolutamente necessárias a todas as Constituições, no sentido de consagrar o respeito à dignidade humana, garantir a limitação de poder e visar ao pleno desenvolvimento da personalidade humana

Podemos concluir, assim, que alguns direitos humanos são também fundamentais, bem como que alguns direitos fundamentais são também direitos humanos. Todavia, essa lógica não se aplica a todos os direitos. SARLET (2006, p. 35 e 36) sobre a diferenciação entre ambos:

Direitos do ser humano que são reconhecidos e positivados na esfera do direito constitucional positivo de um determinado Estado (caráter nacional). Diferem dos direitos humanos - com os quais são frequentemente confundidos - na medida em que os direitos humanos aspiram à validade universal, ou seja, são inerentes a todo ser humano como tal e a todos os povos em todos os tempos, sendo reconhecidos pelo Direito Internacional por meio de tratados e tendo, portanto, validade independentemente de sua positivação em uma determinada ordem constitucional.

Para o fim do presente artigo, passa-se a adentrar o estudo dos direitos fundamentais, os quais alicerçam, em segundo plano, o direito social à educação e à proteção das pessoas deficientes, objeto específico das presentes notas. 


\section{DOS DIREITOS FUNDAMENTAIS}

Feita esta necessária introdução e diferenciação, necessário a verificar os direitos fundamentais. No Brasil, estão previstos no Título II da Constituição, que conta com cinco capítulos, a saber: I - Dos Direitos E Deveres Individuais E Coletivos; II - Dos Direitos Sociais; III - Da Nacionalidade; IV - Dos Direitos Políticos; V - Dos Partidos Políticos.

Os direitos fundamentais espelham os direitos mais caros, imprescindíveis e importantes para o país. Sua importância é traduzida e estampada, já no segundo título, nos primeiros artigos $5^{\circ}$ a $17^{\circ}$, como reforça BELTRAMELLI NETO (2014, p.31).

Por espelharem o que representa de mais importante e caro a uma determinada sociedade, os direitos fundamentais têm diversas características, sendo algumas delas abordadas sinteticamente abaixo.

\subsection{DO CARÁTER HISTÓRICO}

O ilustre professor BOBBIO (1992, p. 5 a p.19), assim assevera sobre o caráter histórico:

\footnotetext{
Os direitos do homem, por mais fundamentais que sejam, são direitos históricos, ou seja, nascidos em certas circunstâncias, caracterizadas por lutas em defesa de novas liberdades contra velhos poderes, e nascidos de modo gradual, não todos de uma vez e nem de uma vez por todas. (...) o que parece fundamental numa época histórica e numa determinada civilização não é fundamental em outras épocas e em outras cultuas.
}

Por exemplo, a Constituição Federal brasileira de 1988 foi concebida logo após anos de ditadura militar. Por conta deste contexto histórico, é inegável que brade a liberdade de forma mais intensa que outros ordenamentos, como pode ser visto, por exemplo, já nos incisos III e IV de seu artigo $5^{\circ}$

\subsection{DO CARÁTER UNIVERSAL}

Sobre a universalidade, como são os direitos mais importantes a uma determinada sociedade, todos os seres humanos daquela são titulares destes direitos indiscriminadamente. GONÇALVES (2012, p. 252) aduz que: 
Os direitos fundamentais são direitos subjetivos de todos os indivíduos de uma sociedade que se reconhece livre e igual, devem ser efetivados na mesma medida para todos, sem exceção.

\subsection{DA CONCORRÊNCIA}

Quanto a concorrência, os direitos fundamentais concorrem entre si. Ou seja, em determinados momentos os direitos fundamentais podem entrar em rota de colisão (liberdade de expressão e dignidade da pessoa humana). Nestes casos, não há uma regra geral que aponte qual prevalece sobre outro.

\subsection{DA IMPRESCRITIBILIDADE, INALIENABILIDADE $\quad \mathrm{E} \quad \mathrm{DA}$ IRRENUNCIABILIDADE}

Os direitos fundamentais, como já dito, representam o que há de mais importante para determinada sociedade. Por esta razão, teoricamente a eles não pode ser atribuído valor econômico, não podendo ser transferidos, renunciados, negociados, podendo ser sempre exercidos. Todavia, como bem exemplificado por ALEXANDRINO e PAULO (2008, p. 102), em alguns casos admite-se sua renúncia ainda que temporária:

o que ocorre nos programas de televisão conhecidos como reality shows (Big Brothrer Brasil, por exemplo), em que as pessoas participantes, por desejarem receber o prêmio oferecido, renunciam, durante a exibição do programa, à inviolabilidade da imagem, da privacidade e da intimidade (art. $\left.5^{\circ}, \mathrm{X}, \mathrm{CF}\right)$.

De se destacar, ainda a característica de que os direitos fundamentais não podem ser diminuídos. Assim, podem ser pontuados como uma limitação constitucional à atuação legislativa e judiciária. Não podem, assim, ser revogados ou limitados. Nas palavras de PIOVESAN $(2013,155)$ :

A aplicação progressiva dos direitos econômicos, sociais e culturais resulta a cláusula de proibição do retrocesso social, como também de proibição da inação ou omissão estatal, na medida em que é vedado aos Estados o retrocesso ou a inércia continuada no campo da implementação de direitos sociais.

\subsection{DA EFICÁCIA}


Inicialmente, os direitos fundamentais foram concebidos, especialmente no Brasil, como dito, em momento histórico atribulado, também como um freio ao estado, de forma a limitar seus poderes e garantir direitos aos cidadãos. Em outras palavras, podese dizer que limitaria a atuação de uma posição de maior poder (estado) para uma de menor poder (cidadãos).

Contudo, como se sabe, a eventuais violações aos direitos fundamentais não de dá apenas de forma vertical, mas também horizontal. Pode-se dizer, de outra forma, que os direitos fundamentais devem ser garantidos não só pelo Estado, mas por todos os sujeitos de direito.

Esta aplicação horizontal (entre iguais) dos direitos fundamentais teve seu início na Alemanha do século XX, com o Caso Lüth (Lüth-Urteil, BVerfGE 7, 198, de 15 de janeiro de 1958). Nele, Erich Lüth, crítico de cinema, encorajou a população a boicotar determinado filme, tendo sido processado e derrotado em todas as instâncias ordinárias da justiça alemã, sob o argumento da ordem pública, garantido pela legislação civil, tendo o caso ido até a Corte Constitucional, onde entendeu-se que o direito fundamental à liberdade de expressão deveria prevalecer sobre a regra do ordenamento civil que defendia a ordem pública. Neste sentido, SARMENTO (2008, p. 193-194):

De fato, parece indiscutível que se a opressão e a violência contra a pessoa provêm não apenas do Estado, mas de uma multiplicidade de atores privados, presentes em esferas como o mercado, a família, a sociedade civil e a empresa, a incidência dos direitos fundamentais na esfera das relações entre particulares se torna um imperativo incontornável.

\subsection{DAS GERAÇÕES OU DIMENSÕES DOS DIREITOS FUNDAMENTAIS}

Com sua diferenciação proveniente do momento histórico em que foram concebidos, costuma-se diferenciar os direitos fundamentais em três dimensões ou gerações, a saber: primeira, segunda e terceira. Nas palavras de ARAUJO e NUNES JUNIOR (2005, p. 109-110):

Os direitos fundamentais podem ser conceituados como a categoria jurídica instituída com a finalidade de proteger a dignidade humana em todas as dimensões. Por isso, tal qual o ser humano, tem natureza polifacética, buscando resguardar o homem na sua liberdade (direitos individuais), nas suas necessidades (direitos sociais, econômicos e culturais) e na sua preservação (direitos relacionados à fraternidade e à solidariedade). 
Apesar de inicialmente ter-se adotado a nomenclatura gerações para os direitos fundamentais, há um certo movimento no sentido de alterar-se a nomenclatura para dimensões, sob a justificativa de que o termo gerações poderia induzir a uma falsa ideia de renovação dos mesmos com o abandono dos mais antigos. Como ensina SARLET (2006, p. 55):

\begin{abstract}
Assim sendo, a teoria dimensional dos direitos fundamentais não aponta, tãosomente, para o caráter cumulativo do processo evolutivo e para a natureza complementar de todos os direitos fundamentais, mas afirma, para além disso, sua unidade e indivisibilidade no contexto do direito constitucional interno e, de modo especial, na esfera do moderno 'Direito Internacional dos Direitos Humanos.
\end{abstract}

\title{
2.8 DOS DIREITOS DE PRIMEIRA GERAÇÃO OU DIMENSÃO
}

Os direitos de primeira geração são aqueles mais primordiais, mais básicos do ser humano, como o direito à vida, à intimidade, à liberdade, etc. Surgiram, em geral, tendo como pano de fundo as ideias do iluminismo. Pode-se dizer representam a queda da monarquia e a ascensão da burguesia, simbolizada na revolução francesa, quando se iniciou uma maior preponderância dos estados liberais sobre os estados totalitários, reconhecendo-se a importância destes direitos e a necessidade de se impor limites ao estado. Neste sentido, os ensinamentos do sempre brilhante BONAVIDES (2006, p. 563564):

Os direitos da primeira geração são os direitos da liberdade, os primeiros a constarem do instrumento normativo constitucional, a saber, os direitos civis e políticos, que em grande parte correspondem, por um prisma histórico, àquela fase inaugural do constitucionalismo do Ocidente.

\subsection{DOS DIREITOS DE SEGUNDA GERAÇÃO OU DIMENSÃO}

Com o cenário de expansão do liberalismo marcado pela aludida Revolução Francesa, sobreveio um período de degradação humana, fazendo-se imperiosa uma preocupação com direitos sociais, econômicos e culturais, inclusive educação e a dignidade da pessoa humana.

Enquanto os direitos de primeira geração têm como símbolo a revolução francesa, os direitos de segunda dimensão encontram na Revolução Industrial seu grande marco. 
Uma vez assegurados e reconhecidos os direitos de primeira dimensão, passouse a uma luta do proletariado por mais direitos, desta vez não os mais básicos, mas ainda assim indispensáveis direitos sociais. Nas palavras de LAFER (2006, p. 127):

É por essa razão que os assim chamados direitos de segunda geração, previstos pelo welfare state, são direitos de crédito do indivíduo em relação à coletividade. Tais direitos - como o direito ao trabalho, à saúde, à educação - têm como sujeito passivo o Estado porque, na interação entre governantes e governados, foi a coletividade que assumiu a responsabilidade de atendê-los

E, no mesmo sentido SARLET (2006, p. 58):

\begin{abstract}
Os direitos de segunda dimensão podem ser considerados uma densificação do princípio da justiça social, além de corresponderem a reivindicações das classes menos favorecidas, de modo especial da classe operária, a título de compensação, em virtude da extrema desigualdade que caracterizava (e, de certa forma, ainda caracteriza) as relações com a classe empregadora, notadamente detentora de um maior ou menor grau de poder econômico.
\end{abstract}

Dentre os direitos de segunda dimensão, como visto, encontram-se os direitos sociais, e, portanto, a educação, tema do presente artigo. Por esta razão, adiante a abordaremos com mais profundidade.

\title{
2.10 DOS DIREITOS DE TERCEIRA GERAÇÃO OU DIMENSÃO
}

Por fim, os direitos de terceira geração. Seu marco é a terceira revolução industrial, que tem a ascensão dos Estados Unidos decorrente principalmente do pós guerra em meados de 1940, passando pela chamada revolução robótica e dos transportes na década de 70, e culminando com a das comunicações na década de 90, com o advento de computadores pessoais e a internet, o que leva a uma globalização da humanidade.

Contam como os direitos coletivos ou difusos, como por exemplo direito ao meio ambiente, à paz, à continuidade, a patrimônios históricos da humanidade, enfim, direitos do coletivo, mas ainda individuais, eis que pertencentes ao todo mas a cada um de nós. Irrepreensível, BONAVIDES (2006, p.569):

Dotados de altíssimo teor de humanismo e universalidade, os direitos da terceira geração tendem a cristalizar-se no fim do século XX enquanto direitos que não se destinam especificamente à proteção dos interesses de um indivíduo, de um grupo ou de um determinado Estado. Tem primeiro por 
destinatário o gênero humano mesmo, num momento expressivo de sua afirmação como valor supremo em termos de existencialidade concreta.

Estabelecidas as premissas alusivas aos direitos fundamentais, propõe-se a análise do direito social à educação no estado brasileiro, sua efetivação no cenário de imperiosa inclusão das pessoas deficientes e, por fim, o desenho da linha que assegura sua efetiva exequibilidade e eficácia, residente no conceito mundialmente adotado das adaptações razoáveis.

\section{OS MARCOS LEGAIS DA EDUCAÇÃO ESPECIAL}

O direito à educação se encontra previsto na Constituição Federal brasileira de 1988 na condição de "direito social", conforme expressa previsão do artigo $6^{\circ}$ do referido diploma legal. Os direitos sociais surgem na condição de segunda geração de direitos fundamentais, seguindo, assim, os de primeira geração, consubstanciados em direitos civis e políticos e, conforme leciona Santos (2012, p. 257), aqueles "se justificam diante da desigualdade dos indivíduos na realidade concreta da vida, notadamente em razão de fatores econômicos e sociais, a exigir a atuação estatal por meio de políticas públicas voltadas para os serviços".

Por este motivo, o Título VIII da Constituição, ao regular a Ordem Social dedicou integralmente a Seção I do Capítulo III à educação, assentando no artigo 205 as diretrizes que deverão reger o desenvolvimento e a efetivação das ações do estado para a satisfação do referido direito social:

Art. 205. A educação, direito de todos e dever do Estado e da família, será promovida e incentivada com a colaboração da sociedade, visando ao pleno desenvolvimento da pessoa, seu preparo para o exercício da cidadania e sua qualificação para o trabalho.

A redação do texto constitucional evidencia o caráter de universalidade do direito social em testilha, no mesmo passo em que explicita a necessidade de que haja o engajamento não somente do poder público, mas da família e de toda a sociedade para sua efetivação.

Adentrando parcialmente no tema objeto do presente artigo, vale dizer, nas linhas gerais da educação especial (sem o que não será possível, então, assenta as premissas para a discussão acerca das “adaptações razoáveis”), a Carta da República 
vigente albergou na redação do artigo 208, inciso III, relevante marco que definiria o rumo das ações do estado e do legislador infraconstitucional ao prever no referido dispositivo que "O dever do Estado com a educação será efetivado mediante a garantia de: (...) III - atendimento educacional especializado aos portadores de deficiência, preferencialmente na rede regular de ensino;"”.

O vetor trazido pela Constituição da República que, evidentemente, não esgotara e não esgotaria a matéria, revelava o direcionamento a ser seguido pelo legislador infraconstitucional no exercício de sua tarefa de criar as condições para o estabelecimento e a execução de políticas públicas afirmativas que, no âmbito da educação, deveriam ser lançadas no sentido de se propiciar o mais assente acolhimento e integração da pessoa portadora de deficiência ao processo de ensino regular, sempre que tal medida se compatibilizasse à efetiva realização do direito do indivíduo. Nesta esteira, conforme ensina Raiol (2012, p. 304):

\begin{abstract}
“A garantia dos direitos concernentes à acessibilidade, à educação, à saúde e ao trabalho, reivindicáveis em prol das pessoas com necessidades especiais, representa a emancipação do Estado Democrático de Direito, no qual está cristalizada a República Federativa do Brasil, como o proclama, no artigo $1^{\circ}$, a Constituição Federal, tendo como fundamento, dentre outros, a dignidade da pessoa humana, considerada como base fundamental dos direitos humanos"
\end{abstract}

A legislação infraconstitucional brasileira, portanto, encarregou-se de municiar o ordenamento dos dispositivos capazes de representar a efetivação do direito social à educação, o que, evidentemente, traz como parte fundamental a educação inclusiva. $\mathrm{O}$ primeiro marco legal pós-constituição federal de 1988 que deve ser frisado está assentado na Lei Federal 7.853 de 24 de outubro de 1989, que, dispôs sobre "o apoio às pessoas portadoras de deficiência, sua integração social", dentre outros assuntos relacionados ao tema. O diploma legal em testilha é um relevante marco no assentamento objetivo de (i) direitos dos cidadãos deficientes e (ii) obrigações do Estado e da sociedade para a satisfação desses direitos. A lei abrange os direitos dos deficientes na área da saúde, do trabalho e, nesta linha, na área da educação, criando claros contornos da atuação das instituições de ensino necessárias para a efetivação de tais direitos, o que se observa na redação do artigo $2^{\circ}$, § único, item I que, ao regular as medidas que deveriam ser priorizadas e atendidas pelo Estado no aspecto educacional, estabeleceu:

\title{
I - NA ÁREA DA EDUCAÇÃO:
}


a) a inclusão, no sistema educacional, da Educação Especial como modalidade educativa que abranja a educação precoce, a pré-escolar, as de $1^{\circ}$ e $2^{\circ}$ graus, a supletiva, a habilitação e reabilitação profissionais, com currículos, etapas e exigências de diplomação próprios;

b) a inserção, no referido sistema educacional, das escolas especiais, privadas e públicas;

c) a oferta, obrigatória e gratuita, da Educação Especial em estabelecimento público de ensino;

Para a devida compreensão, outrossim, da regulação estatal atualmente vigente acerca a educação especial, necessário assentar a importância do fato de que no ano de 1994 o Brasil tornou-se signatário da Declaração de Salamanca, a qual dispõe "Sobre Princípios, Políticas e Práticas na Área das Necessidades Educativas Especiais”.

A convenção representou significativo avanço na consolidação de direitos das pessoas com deficiência, incluindo-se, uma vez mais, diversas diretrizes no âmbito da educação, o que, na prática, reforçou o compromisso do estado brasileiro na atuação por meio de políticas afirmativas para a satisfação dos direitos das pessoas com deficiências, a despeito de ser do ano de 1989 a lei federal n. 7853 que assegurava diversos direitos dos indivíduos e obrigações ao Estado e à sociedade relacionados à educação inclusiva. Neste sentido, estabelecia claramente o Item 3 da Declaração de Salamanca:

3. Nós congregamos todos os governos e demandamos que eles: - atribuam a mais alta prioridade política e financeira ao aprimoramento de seus sistemas educacionais no sentido de se tornarem aptos a incluírem todas as crianças, independentemente de suas diferenças ou dificuldades individuais. - adotem o princípio de educação inclusiva em forma de lei ou de política, matriculando todas as crianças em escolas regulares, a menos que existam fortes razões para agir de outra forma.

O terceiro marco legal relevante para o regime jurídico atualmente regente da educação especial no Brasil está calcado na Convenção Internacional sobre os Direitos das Pessoas com Deficiência ocorrida em Nova Iorque em 2007. Seus preceitos restaram recepcionados no ordenamento brasileiro por meio do Decreto 6.949 de 25 de agosto de 2009 que, então, promulgou a Convenção Internacional sobre os Direitos das Pessoas com Deficiência e seu Protocolo Facultativo, assinados em Nova York, em 30 de março de 2007. Deste modo, necessário ter em mente que as disposições da referida convenção são dotadas de força de norma constitucional, consoante preceituação do artigo art. $5^{\circ}, \S$ $3^{\circ}$ da Constituição Federal. 
Tal como os diplomas legais anteriormente aduzidos na condição de marcos legais da educação especial, a Convenção de Nova Iorque busca reafirmar os direitos das pessoas deficientes, o que faz, inicialmente em seu artigo $1^{\circ}$, assegurando o propósito de adoção de medidas concretas e positivas por parte dos Estados membros no sentido de se "promover, proteger e assegurar o exercício pleno e equitativo de todos os direitos humanos e liberdades fundamentais por todas as pessoas com deficiência e promover o respeito pela sua dignidade inerente.".

No que tange à educação, é claro o intuito de acolhimento integral de todas as pessoas com deficiência, o que fica explícito pelos termos do Artigo 24, alíneas "a" e "d", sendo que no item 5 do referido dispositivo, encontra-se a primeira relevante referência ao que se poderá entender como o contorno à efetivação do direito à educação inclusiva, ou seja, às adaptações razoáveis, o que, contudo, será aprofundado oportunamente neste artigo:

\footnotetext{
5. Os Estados Partes assegurarão que as pessoas com deficiência possam ter acesso ao ENSINO SUPERIOR EM GERAL, treinamento profissional de acordo com sua vocação, educação para adultos e formação continuada, sem discriminação e em igualdade de condições. Para tanto, os Estados Partes assegurarão a provisão de adaptações razoáveis para pessoas com deficiência.
}

Dois são os marcos legais que, por sua relevância, ainda devem ser abordados. No ano de 2012 foi publicada a lei 12.764 de 27 de dezembro daquele ano, sendo este o primeiro diploma que se preocupou em regular, sob o formato e com força de lei, os direitos da pessoa com autismo (transtorno do espectro autista), vez que "Institui a Política Nacional de Proteção dos Direitos da Pessoa com Transtorno do Espectro Autista; e altera o § 3o do art. 98 da Lei no 8.112, de 11 de dezembro de 1990.”.

O último marco legal a ser abordado, assim, refere-se à Lei Federal n. ${ }^{\circ} 13.146$ de 6 de julho de 2015, a qual "institui a Lei Brasileira de Inclusão da Pessoa com Deficiência (Estatuto da Pessoa com Deficiência). Apesar de ser um relevante diploma legal para a educação especial, é válido notar que, ante os marcos legais expostos, os direitos das pessoas com deficiência, inclusive os relacionados à educação, já eram alvo de regulação prévia por meio de diversos outros diplomas legais, razão pela qual o Estatuto em testilha, em verdade, apesar de ter acarretado relevante impacto social, não pode ser considerado o primeiro marco legislativo protetivo dos direitos da pessoa com deficiência, inclusive no que se refere às questões da educação inclusiva.

Necessário relembrar que em verdade, seguindo a sistemática da Lei 7853/89, a Lei 13.146 regulou os direitos dos deficientes por área (direito à educação, direito à saúde, 
direito ao trabalho etc) razão pela dedicou capítulo específico à Educação, arrolando de maneira sistemática e clara diversos direitos de seus destinatário e, consequentemente, deveres do Estado e da sociedade (incluindo-se, aqui, as instituições de ensino) para a efetivação das políticas inclusivas. De todo modo, a clareza de seus termos, agora incorporados, portanto, ao ordenamento jurídico no formato de lei federal abrangente certamente mitigou a possibilidade de ocorrência de discussões acerca dos destinatários da proteção legal conferida pelo Estatuto da Pessoa com Deficiência, ao esclarecer categoricamente em seu artigo $2^{\circ}$ que será entendida como pessoa com deficiência "aquela que tem impedimento de longo prazo de natureza física, mental, intelectual ou sensorial, o qual, em interação com uma ou mais barreiras, pode obstruir sua participação plena e efetiva na sociedade em igualdade de condições com as demais pessoas.”.

Por fim, cumpre destacar que a Lei Federal 9.394 de 20 de dezembro de 1996, que estabeleceu as diretrizes e bases da educação nacional, tratou da educação especial em seu artigo $4^{\circ}$ e no Capítulo V - Da Educação Especial, a partir do artigo 58. Contudo, deixou-se de arrolar esse diploma entre os marcos legais acima destacados pelo fato das disposições constantes da lei federal em questão serem preponderantemente vetores gerais acerca da educação especial, cabendo aos demais diplomas já acima abordados a tarefa de pormenorizar os instrumentos de efetivação da educação especial e dos direitos das pessoas com deficiência relacionados ao processo educacional.

\section{A EDUCAÇÃO ESPECIAL E OS DIREITOS DE SEUS DESTINATÁRIOS}

Adentrando pontualmente aos aspectos da educação especial que são mais relevantes para este artigo, importa salientar que o artigo 58 da Lei Federal 9.394 de 20 de dezembro de 1996 a define como sendo "a modalidade de educação escolar oferecida preferencialmente na rede regular de ensino, para educandos com deficiência, transtornos globais do desenvolvimento e altas habilidades ou superdotação.”.

Sem qualquer dúvida, a análise da Lei Federal que instituiu o Estatuto da Pessoa com Deficiência evidencia a recepção, na legislação ordinária, de valores constitucionais acerca da educação, incluindo-se os preceitos originalmente inseridos no ordenamento pátrio por meio do Decreto 6.949 de 25 de agosto de 2009 que promulgara a Convenção Internacional sobre os Direitos das Pessoas com Deficiência e seu Protocolo Facultativo, assinados em Nova York, em 30 de março de 2007. 
Conforme já mencionado acima, a lei em questão alberga Capítulo próprio para tratar de todos os assuntos relacionados à educação, o que fez a partir do artigo 27, no qual estampa clara e abertamente que "A educação constitui direito da pessoa com deficiência, assegurados sistema educacional inclusivo em todos os níveis e aprendizado ao longo de toda a vida". E, para efetivar o sistema educacional inclusivo, a partir do artigo 28 do mesmo diploma, estabeleceu amplo rol de direitos dos beneficiários, dentre os quais podem ser citados:

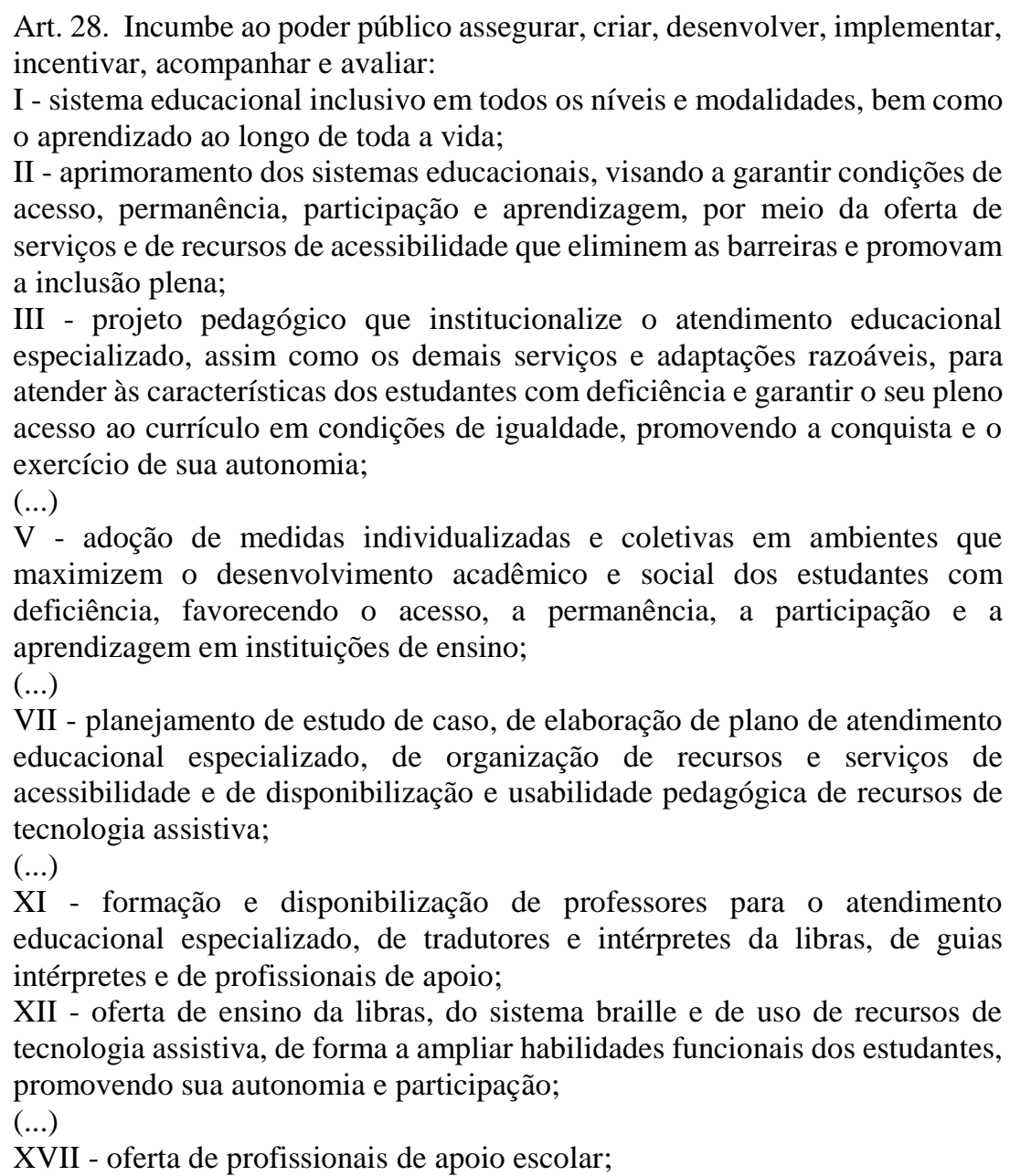

Denota-se que os estabelecimentos de ensino, sejam eles públicos ou privados, diante da realidade instituída pelo texto legal acima transcrito, passaram a ser obrigados a disponibilizar todos e quaisquer recursos, fossem eles humanos e/ou tecnológicos, que fossem necessários para a efetivação do processo da educação especial. Ou seja, desde que relacionados ao processo pedagógico, do estabelecimento de ensino seria o ônus de disponibilizar os recursos e estrutura necessários para a efetivação da educação escolar. 
Evidentemente, tal ônus, ainda que endereçado para a efetivação de um sistema educacional inclusivo, refletiria necessariamente na assunção de obrigações financeiras por parte das instituições de ensino. Aqui, necessário relembrar que o presente artigo focará os impactos financeiros da execução das medidas inerentes à educação especial sobre as escolas privadas, razão pela qual é relevante destacar que, no mesmo passo em que criou tais obrigações para os estabelecimentos, a Lei Federal 13.146 acertadamente proibiu as escolas de promoverem a cobrança de quaisquer valores adicionais dos alunos que ensejassem a necessidade de satisfação de tais despesas, consoante previsão expressa do $\S 1^{\circ}$ do artigo 28 do acima aludido diploma legal ${ }^{4}$.

Deste modo, observa-se que a efetivação do sistema educacional inclusivo, estabelecido (e imposto) pela legislação passa necessariamente pela absorção dos impactos econômicos decorrentes das despesas geradas pelas medidas que obrigatoriamente devem ser adotadas pelas escolas na execução da educação especial, sendo certo que a legislação, contudo, assegurou um instrumento capaz de evitar potenciais desequilíbrios inerentes ao processo inclusivo, o qual, contudo, deve ter sua aplicação cercada de cautela e razoabilidade.

\section{A EDUCAÇÃO ESPECIAL E AS ADAPTAÇÕES RAZOÁVEIS}

Evidentemente, a educação inclusiva possui seus contornos e a tarefa de se catalogar respostas a potenciais problemas afetos à inclusão é simplesmente inexequível. Parte-se aqui da premissa de que inafastável é a aplicação de todas as preceituações relacionadas à educação especial, seja por força do que estabelece o artigo $28, \S 1^{\circ}$ da lei federal 13.146/2015, seja pelo que dispõe o artigo $7^{\circ}$, I da lei federal 9.394/96 ${ }^{5}$.

Neste contexto, estabelecida também a premissa de que o sistema educacional é inclusivo, está-se diante de uma tensão de forças representadas, por um lado, pelo caráter cogente e impositivo do direito fundamental à educação e, portanto, à educação especial e, de outro, da necessidade de absorção dos impactos financeiros decorrentes das despesas adicionais geradas para o cumprimento de todas as obrigações que o estabelecimento de

\footnotetext{
4 “Às instituições privadas, de qualquer nível e modalidade de ensino, aplica-se obrigatoriamente o disposto nos incisos I, II, III, V, VII, VIII, IX, X, XI, XII, XIII, XIV, XV, XVI, XVII e XVIII do caput deste artigo, sendo vedada a cobrança de valores adicionais de qualquer natureza em suas mensalidades, anuidades e matrículas no cumprimento dessas determinações."

5 "Art. $7^{\circ} \mathrm{O}$ ensino é livre à iniciativa privada, atendidas as seguintes condições:

I - cumprimento das normas gerais da educação nacional e do respectivo sistema de ensino;”
} 
ensino deve assumir para, justamente, efetivar o processos inclusivo. E, conforme visto, a tensão ganha maior relevo ao se sopesar que os estabelecimentos particulares são, repita-se, acertadamente, proibidos de cobrar quaisquer valores adicionais dos contratantes de seus serviços para fazer frente a despesas que sejam geradas no atendimento especial dos alunos merecedores deste regime educacional.

A relevância acima aludida ganha ainda maior repercussão ao e sopesar que a rede privada de ensino exerce papel extremamente relevante no atendimento e alunos merecedores da educação especial, sendo inafastável que as escolas da rede privada foram impactadas pelas medidas (cogentes, reitera-se) alusivas à efetivação da educação inclusiva.

Dentro deste cenário, vale relembrar que o direito à educação, na condição de direito de segunda geração, é marcado pela limitabilidade que, conforme leciona Santos (2012, p. 258) "significa que o exercício dos direitos fundamentais também está submetido a limites, tendo como parametrizadores os direitos do outro.”. A situação ora posta da limitabilidade é totalmente nítida ao se tratar da efetivação do direito à educação, incluindo-se à educação especial, nesta hipótese sob a veste da adaptação razoável. Inicialmente, o Decreto 6.949 de 25 de agosto de 2009, ao afirmar o direito à igualdade e não discriminação dos portadores de deficiência, estabeleceu em seu artigo $5^{\circ}$ que "A fim de promover a igualdade e eliminar a discriminação, os Estados Partes adotarão todas as medidas apropriadas para garantir que a adaptação razoável seja oferecida." e ficou a cargo do artigo $2^{\circ}$ definir que:

\footnotetext{
“Adaptação razoável” significa as modificações e os ajustes necessários e adequados que não acarretem ônus desproporcional ou indevido, quando requeridos em cada caso, a fim de assegurar que as pessoas com deficiência possam gozar ou exercer, em igualdade de oportunidades com as demais pessoas, todos os direitos humanos e liberdades fundamentais;
}

Trata-se, portanto, dos “ajustes necessários e adequados que não acarretem ônus desproporcional ou indevido, quando requeridos em cada caso", evidentemente, voltados à efetivação do direito da pessoa com deficiência. Conforme leciona MADRUGA (2016, p. 201, 202):

O "ajuste razoável" tem sua origem na Lei dos Americanos com Deficiência (ADA), de 1990, que no seu Título I estabelece a obrigação dos empregadores em prover reasonable accommodation (acomodação razoável) para os seus empregadores ou candidatos a emprego, no que tange, por exemplo, a instalações acessíveis, mudança de horários, aquisição e modificação de equipamentos e no fornecimento de intérpretes qualificados. No entanto, desde 
janeiro de 2009 vigoram alterações significativas na ADA destinadas a ampliar o conceito de deficiência e, dessa forma, abranger um número maior de beneficiários (The ADA Amendments Act of 2008). Muito embora o novo texto tenha literalmente rejeitado várias interpretações restritivas quanto à deficiência, até então estabelecidas por tribunais estadunidenses, essas alterações findaram também por diminuir o alcance das medidas de ajuste razoável a cargo do empregador.

Diante disso, a lei 13.146/2015 trouxe à legislação infraconstitucional, de maneira cabal, o conceito da adaptação razoável em seu artigo $3^{\circ}$, IV, oportunidade em que reproduziu textualmente a redação inicialmente constante do artigo $2^{\mathrm{a}}$ do Decreto 6.949. O fato relevante é que a mesma lei ordinária em destaque, em seu artigo 28, III imputou às escolas a obrigação de promover "projeto pedagógico que institucionalize o atendimento educacional especializado, assim como os demais serviços e adaptações razoáveis, para atender às características dos estudantes com deficiência”, do que se conclui que o conceito de adaptação razoável é ínsito à efetivação da educação especial.

Consequentemente, é inegável a relevância da análise detida dos elementos que, em cada caso, preencherão o conceito dos ajustes necessários, sobretudo porque de nada adianta alocar a efetivação de direitos sociais, como o da educação, em um universo desatrelado das circunstâncias limitadoras dos recursos disponíveis para o exercício da atividade empresarial, seja ela privada ou não. Para Rousseau e Mackaay (2015), a atividade empresarial e, consequentemente, a análise econômica está assentada na escassez de recursos, na escolha racional e na incerteza. Por isso, o exercício de escolhas que não condigam com a ideia de maximização dos benefícios que podem advir do uso dos recursos limitados disponíveis, certamente não propiciará seu melhor alocamento na economia e, assim, colocará em risco a própria sustentabilidade da atividade econômica.

Esse exercício se faz necessário inclusive nos casos de mitigação de conflitos de interesses relacionados à satisfação de direitos sociais, tal como o à constitucionalmente assegurado à educação especial. Os estabelecimentos de ensino não podem simplesmente se furtar ao cumprimento da legislação ao argumento de que não possuem condições econômicas de ofertar a estruturação necessária para o atendimento da legislação vertente acerca da educação especial.

Contudo, também é certo que, a fim de trazer uma válvula de equilíbrio entre a satisfação dos direitos sociais à educação e as condições mínimas de sustentabilidade da atividade empresarial, o conceito das adaptações razoáveis - manifestamente influenciado pela limitabilidade dos direitos fundamentais - preenchido pelos elementos concretos de cada caso, poderá representar a fórmula para a assecuração justa e equilibrada das 
providências que efetivamente deverão ser adotadas pela instituição de ensino para a efetivação dos direitos do aluno afetos à educação especial.

\section{CONCLUSÃO}

O conceito não representa uma fórmula fechada, na medida em que sua aplicação somente pode ser realizada a partir da análise dos dados de cada caso concreto, sobretudo porque, conforme visto, as adaptações razoáveis são aquelas incapazes de acarretar ônus indevido e desproporcional, até porque tais situações poderiam levar, inclusive, à inviabilidade de manutenção das atividades da escola. Evidentemente, as adaptações razoáveis não podem ser entendidas ou empregadas pelas instituições de ensino como subterfúgio pelas para o devido, lídimo e estrito cumprimento da legislação que rege a educação especial.

Inafastável é o entendimento de que a satisfação dos direitos do indivíduo, tendo em vista a limitabilidade dos direitos fundamentais, não pode produzir desequilíbrio tamanho capaz de impactar a sustentabilidade da atividade das escolas que, em muitas situações, tal como se observa em qualquer outro ramo do setor econômico, são empresas frágeis no aspecto do equilíbrio financeiro, incapazes de absorver despesas extravagantes desproporcionais às suas receitas.

É necessário que, tal como outros direitos fundamentais, a satisfação do direito à educação seja realizada de maneira a se harmonizar à realidade da atividade empresarial da escola da rede privada, na medida em que o desatendimento ao conceito da adaptação razoável ensejará, em efeito cascata, a inviabilidade da manutenção da atividade da escola e, assim, atingirá a própria regularidade do sistema educacional, tendo em vista a manifestamente relevante função desempenhada pela rede privada de ensino no Brasil. 


\section{REFERÊNCIAS}

BRASIL. Presidência da República. Constituição da República Federativa do Brasil de 1988. Diário Oficial de União, Brasília, 05/10/1988. Disponível em http://www.planalto.gov.br/ccivil_03/constituicao/constituicaocompilado.htm. Acesso em 13/02/2019.

BRASIL. Presidência da República. Lei n. 7.853 de 24 de outubro de 1989. Estabelece as diretrizes e bases da educação na Dispõe sobre o apoio às pessoas portadoras de deficiência, sua integração social, sobre a Coordenadoria Nacional para Integração da Pessoa Portadora de Deficiência - Corde, institui a tutela jurisdicional de interesses coletivos ou difusos dessas pessoas, disciplina a atuação do Ministério Público, define crimes, e dá outras providências. Diário Oficial de União, Brasília, 25/10/1989. Disponível em http://www.planalto.gov.br/ccivil_03/leis/L7853.htm. Acesso em 13/02/2019.

BRASIL. Presidência da República. Lei n. 9.394 de 20 de dezembro de 1996. Estabelece as diretrizes e bases da educação nacional. Diário Oficial de União, Brasília, 23/12/1996. Disponível em https://www.planalto.gov.br/ccivil_03/Leis/L9394.htm. Acesso em 13/02/2019.

BRASIL. Presidência da República. Decreto n. 6.949 de 25 de agosto de 2009. Disponível em http://www.planalto.gov.br/ccivil_03/_Ato20072010/2009/Decreto/D6949.htm. Acesso em 13/02/2019.

BRASIL. Presidência da República. Lei n. ${ }^{0} 12.764$ de 27 de dezembro de 2012. Disponível em Diário Oficial de União, Brasília, 26/08/2009. Acesso em 13/02/2019.

BRASIL. Presidência da República. Lei n. 13.146 de 6 de julho de 2015. Institui a Lei Brasileira de Inclusão da Pessoa com Deficiência (Estatuto da Pessoa com Deficiência). Diário Oficial de União, Brasília, 07/07/2015. Disponível em http://www.planalto.gov.br/CCIVIL_03/_Ato2015-2018/2015/Lei/L13146.htm. Acesso em 13/02/2019. 
ALEXANDRINO, Marcelo e PAULO, Vicente. Direito Constitucional Descomplicado", 2a ed. Niterói: Impetus, 2008.

ARAUJO, Luiz Alberto David; NUNES JÚNIOR, Vidal Serrano. Curso de Direito Constitucional. 9. ed. São Paulo: Saraiva, 2005.

BELTRAMELLI NETO, Silvio. Direitos humanos. Salvador: Juspodivm, 2014.

BOBBIO, Norberto. A Era dos Direitos. Rio de Janeiro: Campus, 1992.

BONAVIDES, Paulo. Curso de direito constitucional. 18. ed. São Paulo: Malheiros, 2006.

COMPARATO, Fábio Konder. A afirmação história dos direitos humanos. São Paulo: Saraiva, 2003.

DEClaraÇÃo De SAlamanCA. Sobre Princípios, Políticas e Práticas na Área das Necessidades Educativas Especiais. Salamanca, Espanha. 10/06/1994. Disponível em https://unesdoc.unesco.org/ark:/48223/pf0000139394. Acesso em 12/02/2019.

FERNANDES, Bernardo Gonçalves. Curso de Direito Constitucional. Lúmen Júris Editora. Rio de Janeiro. 2012.

HERKENHOFF, João Baptista. Curso de direitos humanos: gênese dos direitos humanos. Rio de Janeiro: Acadêmica, 1994.

JUCÁ, Francisco Pedro; KNOERR, Fernando Gustavo; MONTESCHIO, Horácio. DIREITOS HUMANOS E INCLUSÃO SOCIAL. Revista Juridica, [S.1.], v. 52, n. 3, p. 478 - 507, fev. 2019. ISSN 2316-753X. Disponível em: <http://revista.unicuritiba.edu.br/index.php/RevJur/article/view/3270/371371778>. Acesso em: 19 abr. 2020. doi:http://dx.doi.org/10.21902/revistajur.2316-753X.v52i3.3270.

LAFER, Celso. A reconstrução dos direitos humanos: um diálogo com o pensamento de Hannah Arendt. 6. ed. São Paulo: Companhia das Letras, 2006. 
LEITE, Carlos Henrique Bezerra. Direitos humanos. 2. ed. Rio de Janeiro: Lumen Juris, 2011.

MACKAAY, Ejan; ROUSSEAU, Stéphane. Análise Econômica do direito. Tradução Rachel Sztajn. $2^{a}$ ed. São Paulo. Atlas, 2015.

MADRUGA, Sidney. Pessoas com deficiência e direitos humanos: ótica da diferença e ações afirmativas. 2. ed. São Paulo. Saraiva, 2016.

MORAES, Alexandre de. Direitos humanos fundamentais. 9. ed. São Paulo: Atlas, 2011.

PIOVEZAN, Flávia. Direitos humanos e o direito constitucional internacional. $14^{\mathrm{a}}$. ed., ver. e atual.- São Paulo: Saraiva, 2013.

RAIOL, Raimundo Wilson Gama. Acessibilidade Física, Educação, Saúde e Trabalho: integrantes do mínimo existencial indispensável às pessoas com necessidades especiais, à luz dos direitos humanos e de fundamentos constitucionais, na era da globalização. In MATTOS NETO, Antonio José de. (org). Direitos humanos e democracia inclusiva. São Paulo: Saraiva. 2012.

SANTOS, Luiza do Socorro Silva dos. A Importância da Democratização da Política Judiciária para a Defesa dos Direitos Fundamentais na Sociedade de Riscos e Perigos Globalizados. In MATTOS NETO, Antonio José de. (org). Direitos humanos e democracia inclusiva. São Paulo: Saraiva. 2012.

SARLET, Ingo Wolfgang. A eficácia dos direitos fundamentais. $6^{\mathrm{a}}$ ed. Porto Alegre: Livraria do Advogado, 2006.

SARMENTO, Daniel. A vinculação dos Particulares aos Direitos Fundamentais no Direito Comparado e no Brasil. In A Nova Interpretação Constitucional Ponderação, Direitos Fundamentais e relações Privadas. $3^{\text {a }}$ edição. Org. Luiz Roberto Barroso. Rio de Janeiro: Renovar. 2008. 
